AWARD ACCOUNTS SPSJ Award Accounts

\title{
Development of Aromatic Polymer Electrolyte Membrane with High Conductivity and Durability for Fuel Cell
}

\author{
By Kohei Goto, ${ }^{*}$ Igor RoZHANSKII, Yoshitaka YAMAKAWA, \\ Toshihiro OTSUKI, and Yuji NAITO
}

\begin{abstract}
This report describes a design, preparation and evaluation data of a novel polymer electrolyte membrane, which have been successfully developed for the use in fuel cell vehicles (FCV). This membrane is prepared from the aromatic block copolymer, consisting of alternating stiff sulfonic acid-bearing segments and hydrophobic flexible polymeric sub-units. A bicontinuous microphase-separated morphology of the membrane has been attested, contributing to its excellent water resistance with keeping high proton conductivity. The JSR membrane exhibits actually the same chemical stability as a conventional poly(perfluorosufonic acid) one, while outperforming the latter in power output of the fuel cell, life time and temperature range. In particular, a cold start of $\mathrm{FCV}$ have been first demonstrated at $-20^{\circ} \mathrm{C}$, using this material. A manufacturing of the JSR membrane in the semi-industrial scale is established. This technology has been officially approved for the extension through the public road examination. This SPSJ award is given for developing novel aromatic polymer electrolyte membrane with high performance for the practical use.

KEY WORDS: Polymer Electrolyte Membrane / Poly(p-phenylene) / Block Copolymer / Microphase Separated Morphology / Fuel Cell /

FCV /
\end{abstract}

Fuel cells are widely regarded as promising energy sources due to their high energy efficiency in terms of limiting fossil fuel resources. Among them, polymer electrolyte fuel cells (PEFC) can generate electricity with high power density at moderate temperatures, even at room temperature, to offer a significant advantage to other fuel cell systems, e.g., phosphoric acid fuel cells (PAFC), molten carbonate fuel cells (MCFC) and solid oxide fuel cells (SOFC). Many efforts have been devoted into the research and development of PEFC for transportation and stationary applications, as well as in the design of closely related DMFC (direct methanol fuel cells) for the use in portable devices.

PEFC consists of two electrodes, which are separated by the polymer electrolyte membrane. On the anode side, hydrogen dissociates into protons and electrons by the electrochemical reaction with the catalyst on the electrode surface. Protons diffuse through the membrane to the cathode, while electrons are transmitted to the cathode through the electron conductor, creating thereby an electrical current. Polymer electrolyte membrane is a key material governing the power generation of the fuel cell, and it should meet strict requirements as possessing a high proton conductivity closely linked to high power generation ability, high stability and durability in the fuel cell environment, excellent mechanical toughness, high heat endurance, as well as impermeability to fuel gas or liquid.

Poly(perfluorosulfonic acid) membranes (Figure 1) have been widely used as benchmark materials in PEFC. However, the operation temperature of this type of membranes is limited

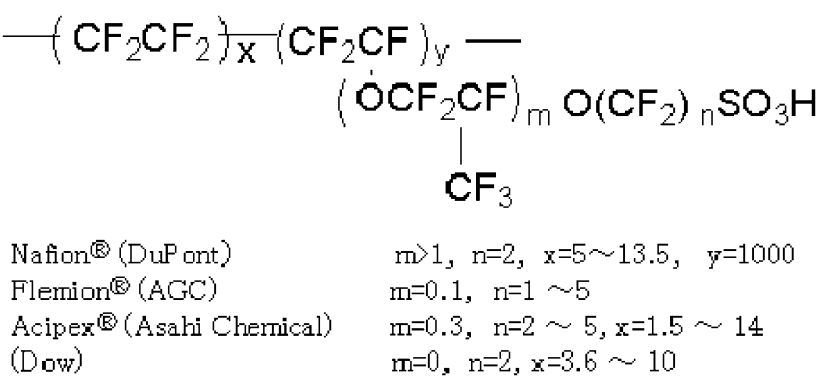

Figure 1. Chemical structure of poly(perfluorosulfonic acid) membranes.

within the range from $0{ }^{\circ} \mathrm{C}$ to $80^{\circ} \mathrm{C}$, because of the drop in conductivity below the freezing point of water and the poor thermo-mechanical properties above $80^{\circ} \mathrm{C}$. Moreover, the durability of membranes is not sufficient to achieve the practical applications in PEFC. There is a strong demand for novel high performance polymer electrolyte membranes, which can extend the operation temperature range and life time.

A great deal of work have been devoted to create high performance polymer electrolyte membranes as an alternative to poly(perfuruorosulfonic acid) ones, employing a wide variety of non-perfluorinated monomers, polymer structures and polymerization techniques. ${ }^{1}$ Nevertheless, there are still unresolved issues of practical applications of these membranes in fuel cell vehicles (FCV) and stationary power units, related to the insufficient performance and durability in devices.

Efforts of several dozens research groups in the world can be 


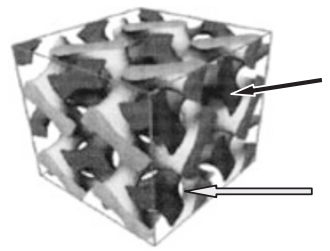

(Hydrophiic sulfonated polymer Segments)

-Interconnected 3-dimensional Network

Formation of Proton-conductive Channels

(HydrophobicNon-sulfonated Polymer Segments)

- Interconnected 3-dimensional Network

Mechanical Reinforcing, Water Resistance

Figure 2. Ideal phase-separated structure with good balance of properties.

roughly divided by a few approaches. Starting from the middle 1970s, the first-generation membranes have been synthesized by direct sulfonation of aromatic polymers, selected from commercially available low-cost aromatic engineering plastics. In some instances, a proper selection of the polymer structure helped to direct an electrophilic sulfonation reaction of the substrate. ${ }^{2}$ However, intrinsic difficulties in controlling the content and substitution position of sulfonic acid groups within polymer would result in poor process reproducibility. From the early 1990s onwards, the second-generation sulfonated polymers have been synthesized from commercially available monomers bearing sulfonic acid groups. ${ }^{3}$ Although a good control of the content and substitution position of the sulfonic acid group could be achieved by this method, it relies on the limited number of commercially available monomers. A variety of membranes of sufficient proton conductivity have been prepared by these approaches, but neither of them could reach the level of the practical use in PEFC. Recently, the third-generation polymers have been prepared from specially designed monomers bearing sulfonic acid groups, which would meet the requirements for the practical use in PEFC. ${ }^{4}$

In continuing these efforts, we have successfully developed a new non-perfluorinated polymer electrolyte membrane with excellent proton conductivity and durability. The backbone of this polymer is composed of alternating sulfonated hydrophilic aromatic blocks and non-sulfonated hydrophobic aromatic blocks, using novel specially designed monomers. This membrane enables an excellent engine performance in FCV, which is difficult to accomplish by conventional poly(perfuruorosulfonic acid) membranes. Also, we have established the polymer synthesis and film manufacturing processes in the semi-industrial scale. Herein, we report the design concept and performance data of the new polymer electrolyte membrane developed by JSR Corporation.

\section{CONCEPT OF POLYMER DESIGN}

The main obstacle in achieving good characteristics in sulfonated polymer membranes is an inevitable increase in water uptake with increasing concentration of proton-conducting sulfonic acid units. Beyond the certain sulfonation degree, an electrolyte membrane tends to absorb so much water, that it negatively affects its mechanical properties and water resistance, down to the loss of integrity and solubility in water. On the other hand, materials with acceptable mechanical strength and water resistance tend to exhibit prohibitively low proton conductivity. In order to circumvent this unfavorable relationship, we adopted a concept of molecular composite, in which a hydrophilic sulufonic acid-bearing polymer is embedded into a hydrophobic non-sulfonated polymer matrix, forming bicontinuous microphase-separated domains.

The ideal membrane morphology to fit this concept would be imagined as a so called 'gyroid' microphase-separated structure $^{5}$ (Figure 2). In this representation, hydrophilic sulfonated polymer segments (black-colored part) form an interconnected 3-dimensional network, which is responsible to the efficient proton transfer, while a complementary network of hydrophobic non-sulfonated segments (white-colored part) provides a reinforcing effect, preventing from excessive swelling in water and enhancing mechanical properties, such as strength and ductility. The best way to achieve such morphology is to employ block copolymers composed of two (or more) incompatible parts.

In this work, we investigated a series of block-copolymers which could be able to adopt the microphase-separated morphologies. In addition, we have synthesized a novel sulfonated monomer to obtain the structure-controlled hydrophilic segment. By this method, we could successfully prepare well-defined sulfonic acid-containing polymers, offering a precise control of the properties of polymer electrolyte membranes.

As an example, Figure 3 shows TEM (Transmission Electron Micrograph) of the polymer electrolyte membrane prepared according to our polymer design concept. Darkcolored and light-colored areas correspond to sulfonated hydrophilic blocks and non-sulfonated hydrophobic blocks, respectively. They are arranged in a bicontinuous fashion, with average size of microphase-separated domains being $c a .10 \mathrm{~nm}$.

\section{POLYMER DESIGN AND SYNTHESIS}

\section{Poly(sulfonic acid) Segment}

The proper molecular structure of the sulfonic acid segment is of primary importance, because it should offer both high proton conductivity and good durability in aggressive environment. From the chemical point of view, this structure should meet the following requirements: (i) high bond energy of the polymer main chain; (ii) high elimination temperature of the 


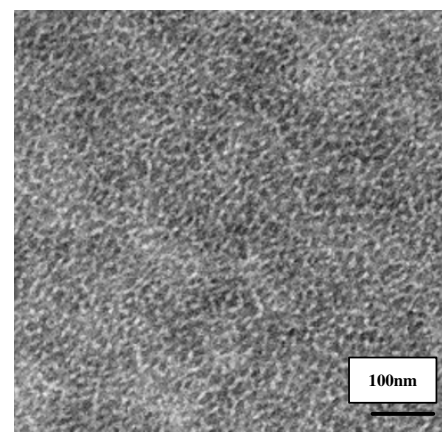

Controlled domain size of $10 \mathrm{~nm}$ order

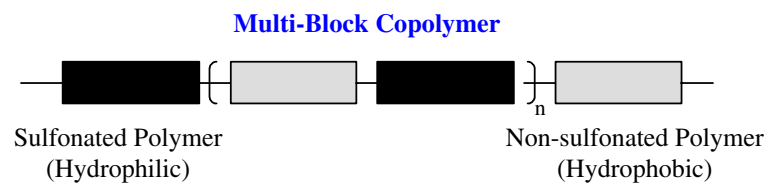

Figure 3. TEM of phase-separated JSR membrane.

sulfonic acid group; and (iii) high concentration/high density of sulfonic acid groups. Properties (i) and (ii) concern durability, while (iii) is responsible to the proton conductivity.

A necessity to attain the high bond energy of the polymer main chain is evident as a means to prevent the chain scission and the subsequent polymer degradation. Comparing $\mathrm{C}-\mathrm{C}$ bond energies in a row of $\mathrm{C}_{6} \mathrm{H}_{5}-\mathrm{C}_{6} \mathrm{H}_{5}(101 \mathrm{kcal} / \mathrm{mol}),{ }^{6} \mathrm{CF}_{3}-\mathrm{CF}_{3}$ $(97 \mathrm{kcal} / \mathrm{mol})^{6}$ and $\mathrm{CH}_{3}-\mathrm{CH}_{3}(83 \mathrm{kcal} / \mathrm{mol}),{ }^{6}$ the former linkage seems to be the most preferable. Accordingly, an introduction of the poly(phenylene) backbone into the sulfonated segment is expected to be a straightforward way to improve the membrane durability.

However, there is an issue of poor solubility of poly(phenylene)s in organic solvents, leading to poor processability. The common method to overcome this problem is an introduction of side chains, which themselves should exhibit sufficient chemical stability to withstand fuel cell environment conditions. We have undertaken a screening of poly( $p$-phenylene)s and poly( $m$-phenylene)s prepared from sulfonated phenoxybenzophenone and benzophenone derivatives. A particular attention was taken to the water resistance of corresponding membranes.

The water resistance data of proton conductive membranes based on poly(phenylene)s are summarized in Figure 4. Apparently, the structure of the main chain is crucial to enhance the water resistance, with rigid poly( $p$-phenylene) backbones being advantageous to randomly bent poly $(m-$ phenylene) ones. Another important factor is the structure of the sulfonated side chain. In this respect, $\operatorname{poly}(p$-phenylene) with 3-benzoylsulfonic acid side chains (left-bottom) shows the best characteristics.

The second important factor is stability of sulfonic acid moieties at elevated temperatures. Sulfonic acids are known to be susceptible to desulfonation reaction which is a reverse to the common electrophilic aromatic sulfonation. ${ }^{7}$ In accordance with the reversibility principle, this undesired reaction is

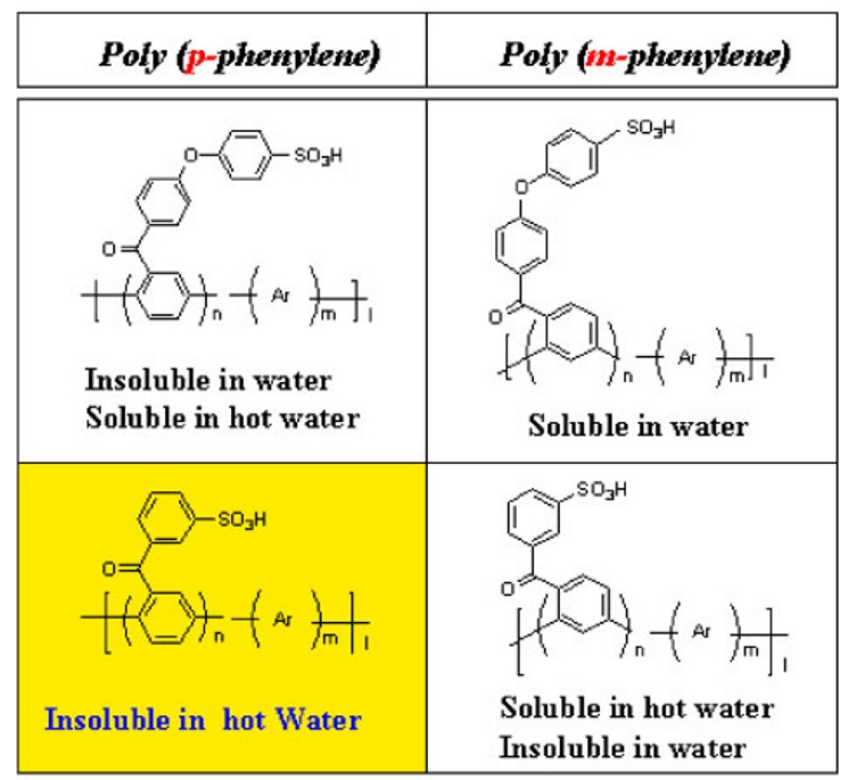

Comparison at approximately the same concentration of $-\mathrm{SO}_{3} \mathrm{H}$

Figure 4. Water resistance data of sulfonated poly(phenylene)s.

facilitated by electron-donating groups, such as oxygen or sulfur. On the other hand, the introduction of electron-withdrawing groups onto aromatic ring could inhibit desulfonation, to be one of solutions to increase the thermal stability of sulfonated aromatics. This consideration is supported by the thermal gravimetrical analysis (TGA) of representative poly(benzenesulfonic acid) polymers, containing electron-donating 4-phenoxy and electron-withdrawing 3-benzoyl substituents (Figure 4, left-top and left-bottom, respectively). Again, the latter polymer shows much higher thermal decomposition temperature $\left(T_{\mathrm{d}}\right)$ compared with the former one $\left(310^{\circ} \mathrm{C} v \mathrm{~s}\right.$ $230^{\circ} \mathrm{C}$, respectively). Moreover, structurally similar 2,5-dichlorobenzophenone is known to exhibit an excellent activity towards dehalogenative aryl-aryl coupling, suggesting polymers of the high molecular weight. ${ }^{8}$

The third factor, i.e., high concentration/high density of sulfonic acid groups, is important from the viewpoint of formation of proton-conductive channels within the polymer matrix. When sulfonated polymer segment with the least equivalent weight (EW) for sulfonic acid is used, it is possible to increase a volume fraction of the hydrophobic segment, improving thereby mechanical properties and water resistance of the membrane with keeping high proton conductivity. Comparative data of EW values for several representative sulfonated repeat units are summarized in Figure 5.

The proposed 2',5'-disubstituted 3-benzoylsulfonic acid shows rather low EW value (260), corresponding to the ion exchange capacity (IEC) of $3.84 \mathrm{meq} / \mathrm{g}$ for homopolymer. Among other classes of polymers, polyimide ${ }^{9}$ and polyether ${ }^{10}$ repeat units exhibit reasonably low EW (288 and 280, respectively), but these polymers are not durable enough to provide a stable performance in fuel cells. The actual chemical structure of perfluorosulfonic acid unit (left in Figure 5) is 


\section{$\mathrm{EW}$ for $-\mathrm{SO}_{3} \mathrm{H}$}

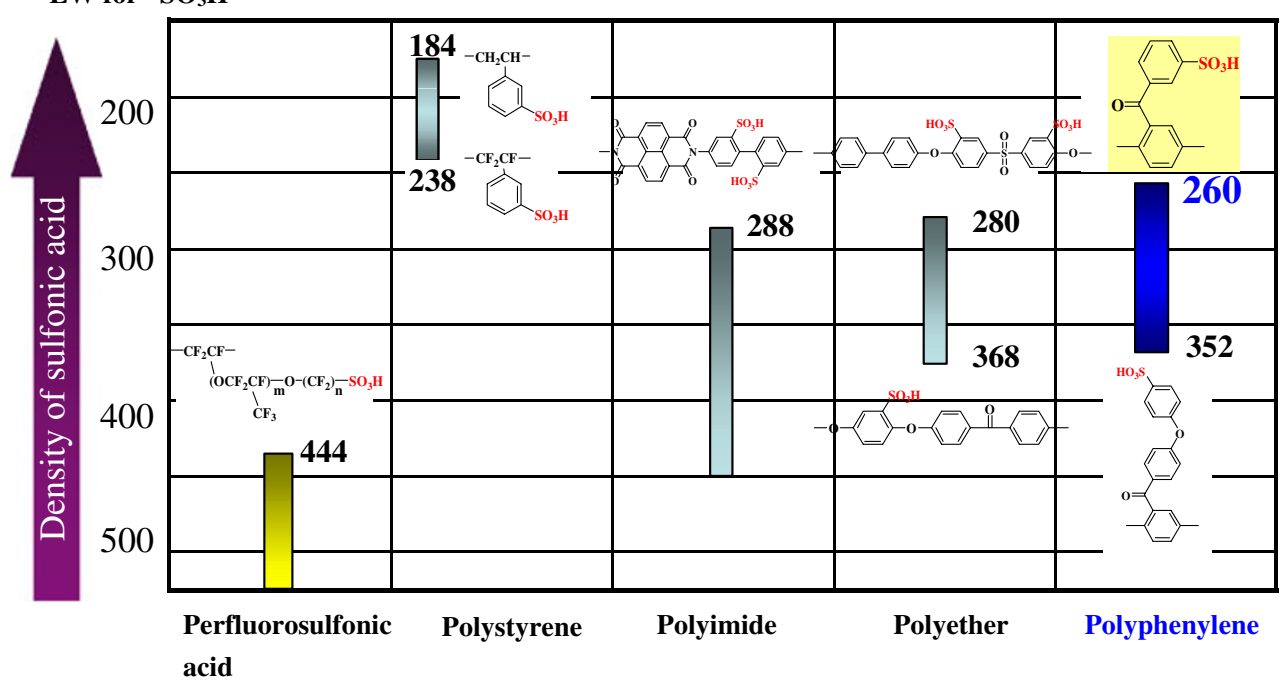

Figure 5. Comparative equivalent weights of sulfonated repeat units.

unknown, and the least possible EW value is estimated from the formula of Figure 1 as 444, to be much higher than the formers. The durability issue restricts greatly the use of sulfonated polystyrene, in spite of its lowest EW (184). Fluorinated polystyrene (238) has not been reported to offer the further progress as well. ${ }^{11}$

\section{Block Copolymer}

In accordance with the basic concept of JSR membrane design, a block copolymer architecture composed of alternating sulfonated and non-sulfonated segments is essential to prevent a decrease of mechanical strength and an increase of swelling in hot water. In the viewpoint of commercial production, the precise control of molecular weight and composition of blockcopolymer is an important issue. In other words, the manufacturing technology of high-molecular weight sulfonated polymer and the reliable quality control techniques are required to be established.

In practice, it is difficult to attain the required high polymerization degree by the direct use of 3-(2,5-dichlorobenzoyl)benzenesulfonic acid as a monomer, as well as its salts. Therefore, there is a need to develop a suitable sulfonic acid precursor in order to increase the polymerization activity. In addition, a necessity to sustain the uniformity of blockcopolymerization suggests the use of hydrophobic monomers in this step. This hydrophobic precursor has been selected from sulfonic esters, which can be obtained by esterification of corresponding sulfonyl chloride.

A two-step approach has been proposed, as outlined in Figure 6. In the first step, the sulfonic ester monomer and the sulfonic ester-free hydrophobic polymer are block-copolymerized to give the precursor copolymer, in which both segments are hydrophobic. Next, the sulfonic ester units are converted to sulfonic acids by the appropriate deprotection reaction to give the block-copolymer comprised of hydrophilic and hydrophobic segments. Following a sequence of processes, an
Termination with chrolobenzoyl units for hydrophobic aromatic polymer

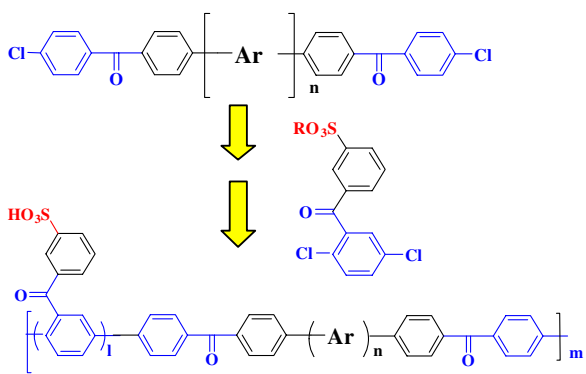

Block Copolymerization and controlling morphology

Figure 6. Synthesis of block copolymer.

aiming sulfonated membrane composed of block copolymer is finally prepared.

In this strategy, a selection of the appropriate structure of the protecting group is important because it should satisfy somewhat contradictory requirements, as follows:

1) It should not interfere with the copolymerization process by any means;

2) It should not undergo any deprotection reactions during copolymerization;

3) After copolymerzation, it must be quantitatively removed under mild conditions in short time.

Figure 7 shows a relationship between the polymerization activity and the ease of deprotection reactions in the series of monomers with various protective groups. Sulfonyl amides and phenylsulfonic esters can polymerize easily, but fail to undergo deprotection, except for very harsh conditions. In case of alkylsulfonic esters, their reactivity towards the polymerization reaction is deceased in the order of primary $>$ secondary $>$ tertiary. There is a tendency for longer alkyl chain of primary sulfonic esters to yield higher molecular weight polymer. On the other hand, the ease of deprotection is arranged in the reverse order, that is, tertiary $>$ secondary $>$ primary. 

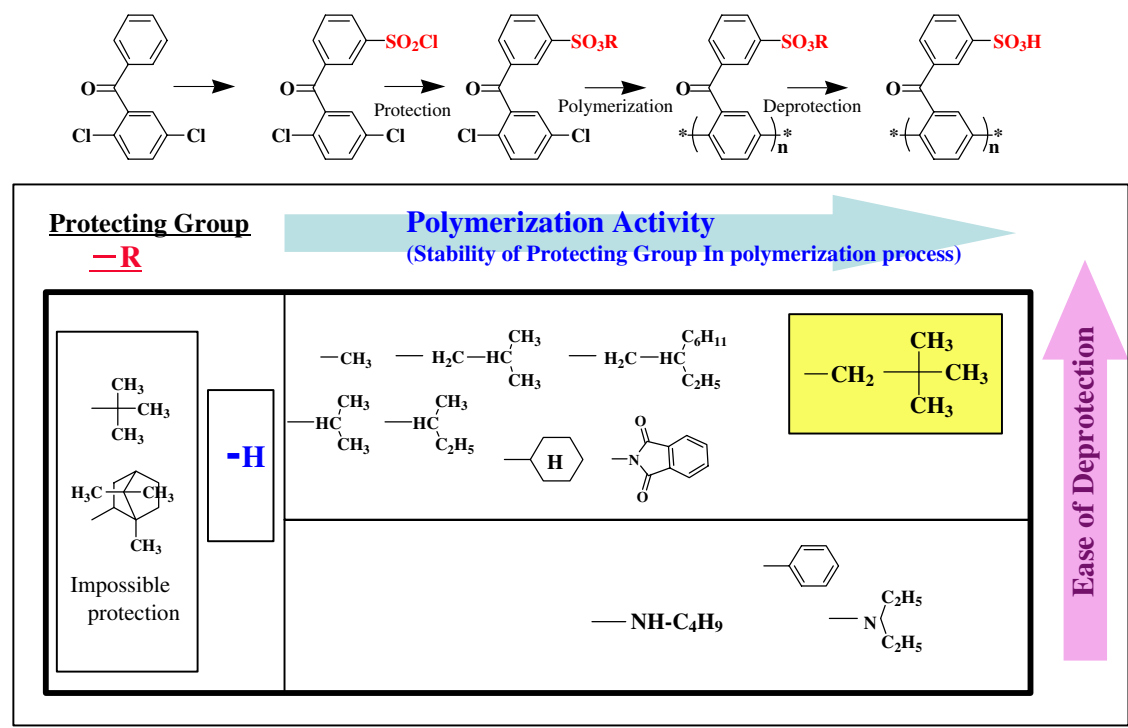

Figure 7. Relationship between the polymerization activity and the ease of deprotection reactions.

Therefore, there is a trade-off relationship between the polymerization degree and the ease of deprotection. However, we have found that the neopentyl (=2,2-dimethylpropyl) group has an optimal combination of properties, arising from steric bulkiness at its primary carbon atom. This protective group is highly stable in the course of polymerization, but can be removed quantitatively under mild conditions with no formation of undesired by-products. As a result of the study, neopentyl 3-(2,5-dichlorobenzoyl)benzenesulfonate has been considered as a monomer of choice to give high molecular weight block copolymers.

A non-sulfonated hydrophobic segment is selected from aromatic engineering plastics, possessing high durability at high temperatures. Keeping in mind strongly acidic environment inside the fuel cell, we do not incorporate hydrolytically labile amide, imide and ester bonds into the polymer structure. Other structural features of these polymers are adjusted in order to promote reduced water sorption, ductile fracture behavior, good solubility and processability of the final polymer. In addition, chain ends of the polymer are terminated with chlorobenzoyl units, which show the same reactivity towards dehalogenative aryl-aryl coupling as a sulfonic ester monomer. Molecular weight measurements and analytical data confirm a formation of the true block copolymer, with its compositions being finely tuned by the feed ratio of comonomers.

The polymer shown in Figure 6 adopts a microphaseseparated morphology upon film preparation, as illustrated by TEM in Figure 3.

\section{The Control of the Hydrophilic/hydrophobic Microphase Separation}

An approach developed by JSR is efficient in controlling the film morphology. The patterns of the microphase separation are governed by following 5 factors: (i) the mass ratio between sulfonated and non-sulfonated sub-units; (ii) the molecular structure of the non-sulfonated polymer block; the lengths of
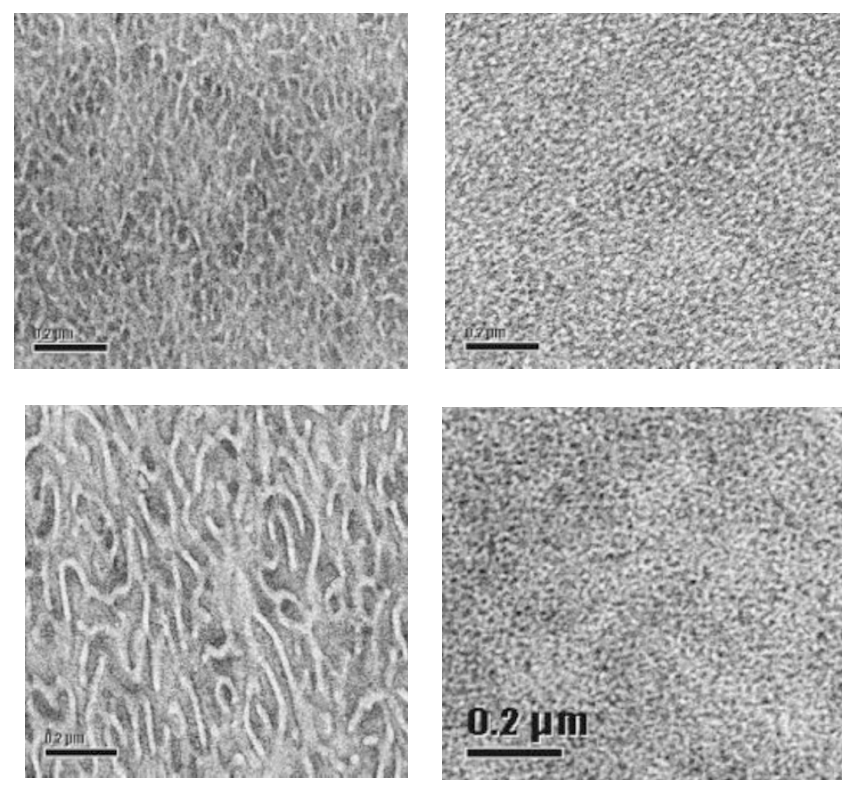

Figure 8. Typical TEM of membranes composed of block copolymers: shorter blocks/low IEC (upper left), longer blocks/low IEC (bottom left), shorter blocks/high IEC (upper right), longer blocks/high IEC (bottom right).

(iii) sulfonated and (iv) non-sulfonated blocks; and (v) the conditions of film-making. The representative TEM images of JSR membranes are shown in Figure 8. As it clearly seen, a variety of morphologies have been obtained in a reproducible way by adjusting the aforementioned parameters.

\section{Manufacturing Technology}

The following new manufacturing technologies have been established through the development of the novel polymer electrolyte membrane:

1. Synthesis of the sulfonated monomer based on 2,5dichlorobenzophenone core, which provides a high 

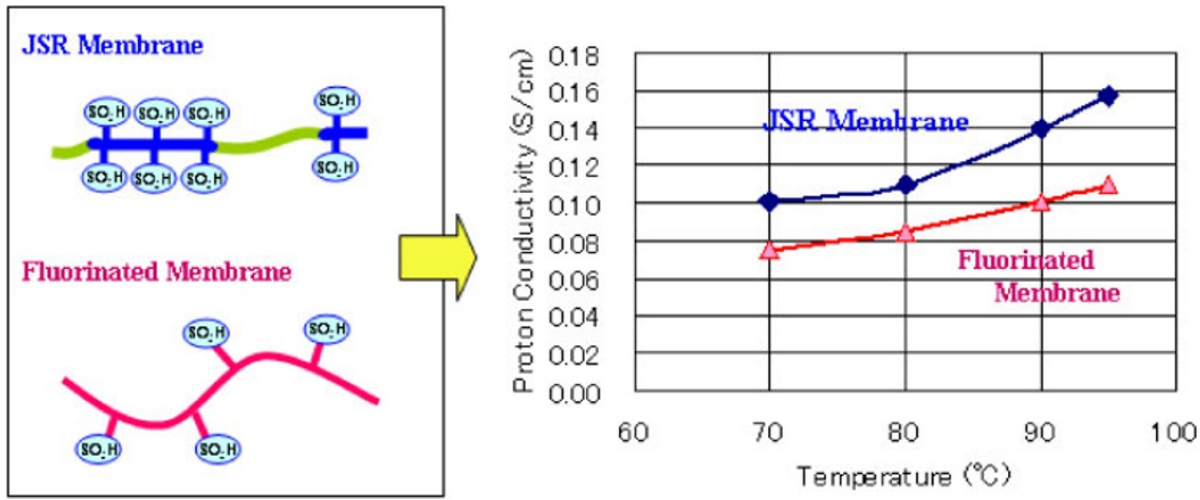

Figure 9. Proton conductivity of membranes at $80 \%$ relative humidity.

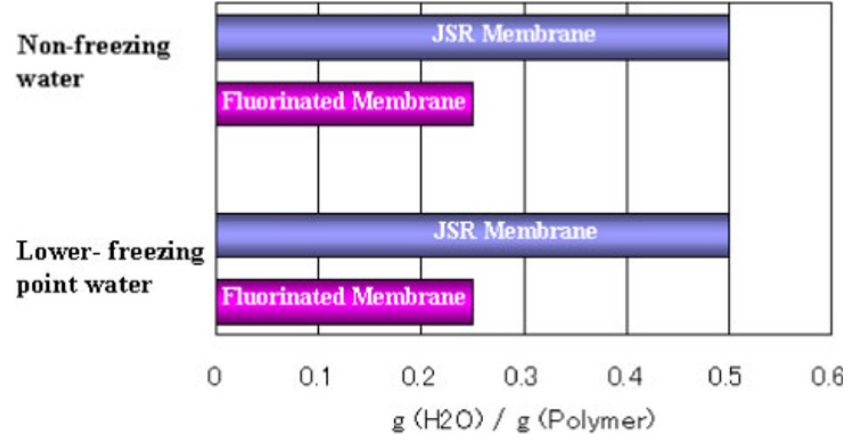

Figure 10. Amounts of bounded water upon soaking in water at $90^{\circ} \mathrm{C}$.

density of sulfonic acid units within hydrophilic segments of the block copolymer.

2. Synthesis of the sulfonated polymer through the protection-deprotection strategy, with using neopentyl ester as a protective group.

3. Synthesis of block copolymers from telechelic chlorobenzoyl-functionalyzed macromonomers and a sulfonic ester based on 2,5-dichlorobenzophenone.

4. Techniques of manufacturing and controlling the predetermined membrane morphology, specifically focused on the chemical structure of the non-sulfonated block, copolymerization and the process of film-making.

\section{PERFORMANCE OF THE POLYMER ELECTRO- LYTE MEMBRANE}

\section{Proton Conductivity}

JSR electrolyte polymer has a rigid structure with high water resistance, making thereby possible to support higher concentration of sulfonic acid groups than the conventional flexible fluorinated polymer. As a result, JSR electrolyte membrane (JSR membrane) is expected to have higher proton conductivity. In Figure 9, the proton conductivity of JSR membrane is shown as a function of temperature, to be $20-50 \%$ higher than the conductivity of the fluorinated membrane (Nafion ${ }^{\circledR} 112$, as a reference).

As previously mentioned, sulfonic acid units in the JSR membrane are confined in high density and high concentration

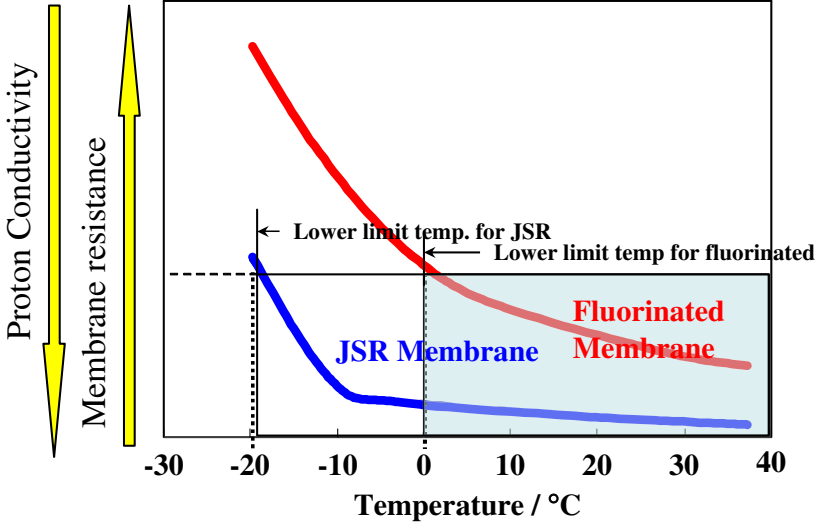

Figure 11. Membrane resistance at lower temperature.

within proton-conductive channels. Such a confinement forces water molecules to have stronger interactions with each other. In consequence, the amount of tightly bound non-freezing water and loosely bound lower-freezing point water is increased. As shown in Figure 10, JSR membrane can hold up to $0.5 \mathrm{~g}$ of non-freezing and $0.5 \mathrm{~g}$ of lower-freezing point water per $1 \mathrm{~g}$ of dry polymer. This amount is about two times higher than that of the fluorinated polymer. Due to the higher content of bounded water, one can expect higher proton conductivity below the freezing point, which should facilitate an engine start at low temperatures in FCV.

In fact, the JSR membrane has low membrane resistance below the freezing point, synonymous to high proton conductivity. The resistance of JSR membrane and reference fluorinated membranes at low temperature is shown in Figure 11. The upper threshold value for the membrane resistance to allow an engine start could be thought as the resistance of the fluorinated membrane at $0{ }^{\circ} \mathrm{C}$. On the other hand, the JSR membrane reaches this threshold value at $-20^{\circ} \mathrm{C}$, low enough to work in cold weather.

\section{Thermal Properties}

Figure 12 shows temperature dependence of dynamic storage elastic modulus under dry conditions at $1 \mathrm{kHz}$. Perfluorinated polymer has a rubber-like low elastic modulus 


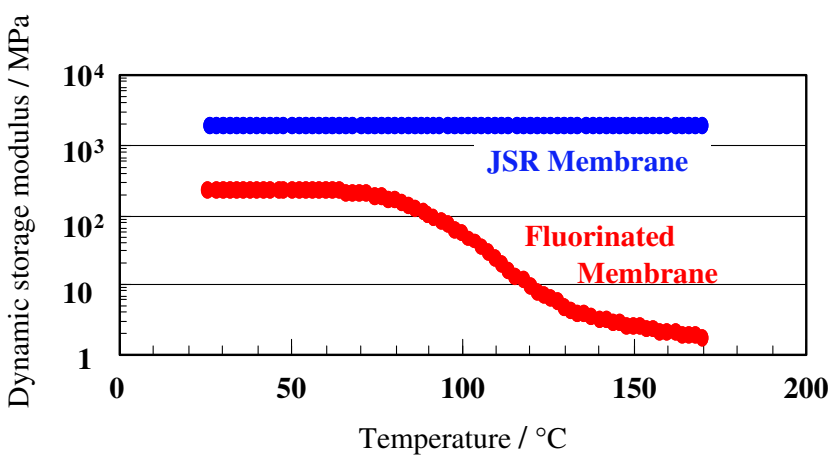

Figure 12. Temperature dependence of dynamic storage modulus at dry condition.

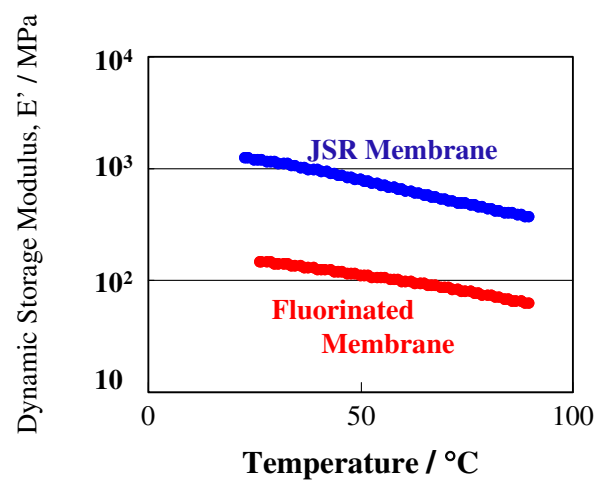

Figure 13. Temperature dependence of dynamic storage modulus in hot water.

of $100 \mathrm{MPa}$ range, going down dramatically near $80^{\circ} \mathrm{C}$ (primary dispersion temperature owing to $T_{\mathrm{g}}$ ). This limits the maximum operating temperature of the perfluorinated polymer membrane to $80^{\circ} \mathrm{C}$. Meanwhile, JSR membrane keeps a high elastic modulus of $1 \mathrm{GPa}$ range ( $c a$. 10 times greater) up to $150^{\circ} \mathrm{C}$. This means that the JSR membrane has a good potential for high temperature operating. As an extreme case of actual operating, a dynamic storage elastic modulus was investigated in hot water (Figure 13). Similar to dry condition tests, the JSR membrane keeps ten times higher modulus than that of the perfluorinated membrane.

In these points of view, the JSR membrane has better thermal properties than the perfluorinated polymer membrane. In fact, the upper operating temperature for this class of membranes is defined by the fuel cell design. A requirement to keep the entire system under atmospheric pressure imposes the limit of $95^{\circ} \mathrm{C}$, just below the boiling point of water. Performance at higher temperatures relies on pressurized cells, which is impractical for the mass production.

\section{Mechanical Properties}

Good mechanical properties constitute essential demands for high membrane endurance. Figure 14 shows stress-strain curves of the JSR membrane and the perfluorinated membrane under ambient conditions $\left(23^{\circ} \mathrm{C}, 50 \% \mathrm{RH}\right)$. JSR membrane has an elastic modulus of $1.8 \mathrm{GPa}$, a tensile stress at yield of $83 \mathrm{MPa}$, a tensile stress at break $130 \mathrm{MPa}$, and an elongation at

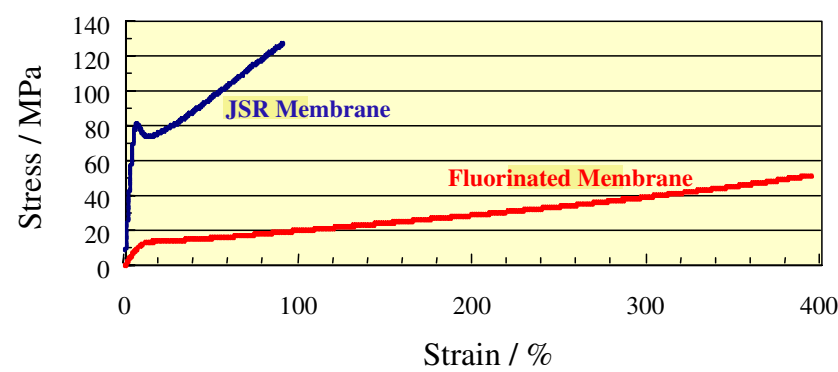

Figure 14. Stress-strain curves at ambient conditions $\left(23^{\circ} \mathrm{C}, 50 \% \mathrm{RH}\right)$.

break of $100 \%$, exceeding the perfluorinated membrane 10 times in elastic modulus and 2.6 times in tensile strength. Furthermore, S-S curve of the JSR membrane shows a yield point, marking ductile fracture behavior. The tensile test results indicate that the JSR membrane is strong and tough. These mechanical properties are mostly governed by the structure of the continuous hydrophobic phase, composed of the aromatic engineering plastic. A microphase-separated morphology of the block copolymer enables this behavior.

\section{Environmental Stability}

Stability tests have been performed under wet and dry conditions at $95^{\circ} \mathrm{C}$ for $1000 \mathrm{~h}$.

As shown in Figure 15, the JSR membrane has neither change of IEC values, no any weight loss. GPC measurements confirm no changes in the molecular weight, as well. This result indicates that the JSR membrane has as good chemical stability as the perfluorinated polymer membrane under the same conditions.

\section{Gas Permeability (gas barrier property)}

Low gas permeability is a desired property for PEFC, because it relates to better fuel efficiency and good endurance characteristics. Figure 16 shows hydrogen gas permeability of the JSR membrane and the perfluorinated polymer membrane, both at room temperature and at $80^{\circ} \mathrm{C}$ (vacuum method). Hydrogen gas permeability of the JSR membrane constitutes from one tenth to one eighth of perfluorinated polymer membrane, meaning very low crossover of the fuel gas for the JSR membrane. Both membranes are more permeable to hydrogen gas at higher temperature. Figure 17 represents oxygen gas permeability of the JSR membrane and the perfluorinated polymer membrane. Both membranes are more permeable at high temperature and highly humid condition. Similar to the previous test, JSR membrane is less permeable to oxygen gas than the perfluorinated polymer membrane by the factor from eight to ten, meaning potentially high tolerance of the JSR membrane to oxidation.

\section{Stability upon Open Circuit Voltage (OCV) Test}

Figure 18 shows changes in an open circuit voltage (OCV) over time $\left(110^{\circ} \mathrm{C}, 50 \% \mathrm{RH}\right)$, characterizing a durability of the PEFC cells. In these OCV conditions, the cell using the perfluorinated polymer membrane maintains a cell voltage for before $120 \mathrm{~h}$, while the cell using our membrane maintains it over $1000 \mathrm{~h}$. High durability of the JSR membrane is proved. 


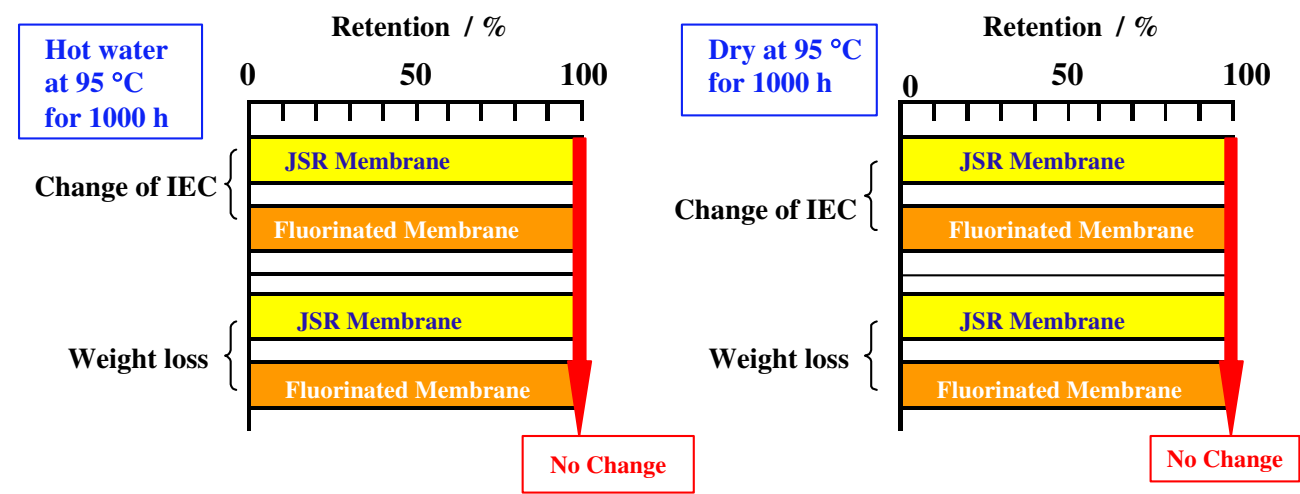

Figure 15. Data of environmental stability tests.

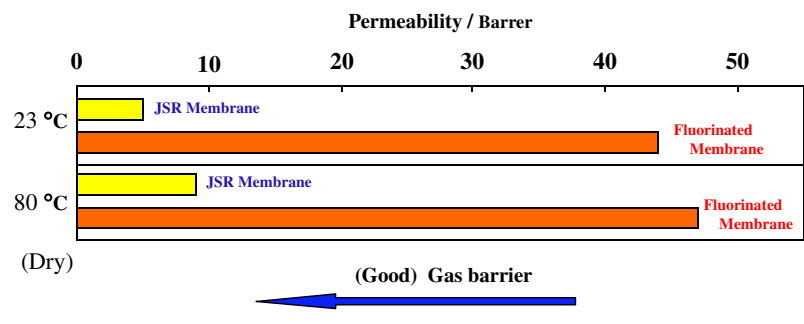

Figure 16. Gas barrier property for hydrogen gas.

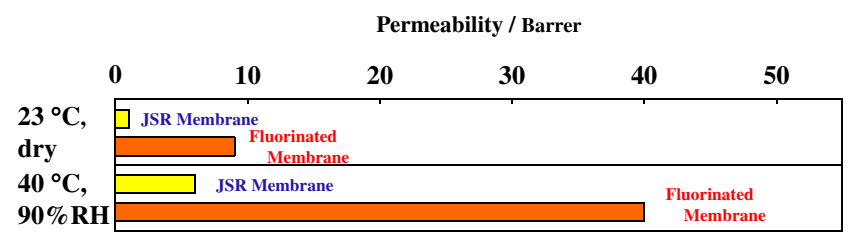

(Good) Gas barrier

Figure 17. Gas barrier property for oxygen gas.

\section{Summary of Properties}

The JSR membrane is almost equal to the perfluorinated polymer membrane in stability, and is much superior to that in the proton conductivity, the cell performance, mechanical properties and gas barrier properties which are key characteristics to PEFC. We have successfully extended the operating temperature range of PEFC cells from $-20^{\circ} \mathrm{C}$ to $95^{\circ} \mathrm{C}$. This greatly helps us to put PEFC in practical use. The PEFC cell durability of the JSR membrane is improved and superior to that of the conventional perfluorinated polymer membrane. Thus, the JSR membrane has advantages over the conventional perfluorinated polymer membrane in PEFC usage.

\section{CONCLUSIONS}

In PEFC that used the perfluorinated electrolyte membrane, the operating range was limited from $0{ }^{\circ} \mathrm{C}$ to $80^{\circ} \mathrm{C}$ because of conductivity and thermal resistance issues. This time, expanding that operating range from $-20^{\circ} \mathrm{C}$ to $95^{\circ} \mathrm{C}$ became possible owing to the development of the aromatic electrolyte mem-

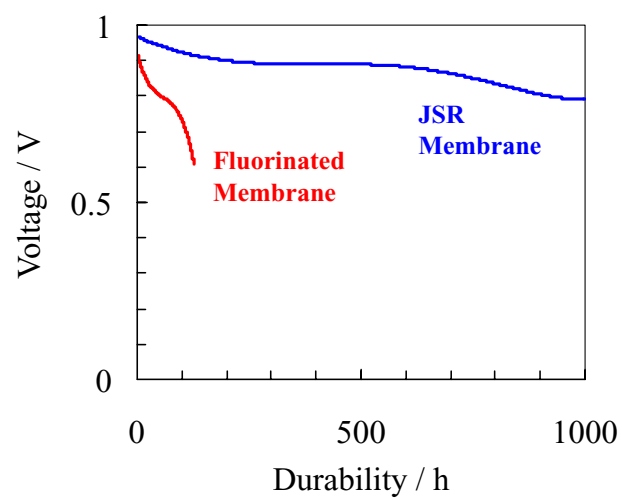

Figure 18. Endurance test upon open circuit voltage $\left(110^{\circ} \mathrm{C}, 50 \% \mathrm{RH}\right)$.

brane with the main chain consisting of poly( $p$-phenylene). Especially, this breakthrough technology has enabled PEFC to work below the freezing point of water, realizing the previously inaccessible goal to drive FCV in winter.

Now, JSR has a plant where the system is manufactured, the quality assurance and shipment systems are maintained, and the product is supplied to the customer (Figure 19). We aim to develop more grades of high-performance membranes, and the research and development is being continued.

\section{Postscript}

JSR released the following content in the press about the development of this electrolyte membrane on January 26, 2006. "12 "JSR developed a new electrolyte membrane, $<$ Aromatic Electrolytic Membrane $>$ by the joint development with Honda R\&D Co., Ltd. «Honda FC STACK》 that FC system of Honda achieved the high temperature operating $\left(95^{\circ} \mathrm{C}\right.$ : so far $\left.80^{\circ} \mathrm{C}\right)$ and the low temperature operating $\left(-20^{\circ} \mathrm{C}\right.$ : so far $\left.0^{\circ} \mathrm{C}\right)$ by using $<$ Aromatic Electrolytic Membrane $>$, and has expanded the power generation temperature range. ${ }^{13}$ This characteristic is big breakthrough to practical use. The low temperature operating is achieved by optimization of polymer structure and increase content of water that doesn't freeze at $0{ }^{\circ} \mathrm{C} .{ }^{14}$ That STACK shows four times high-temperature durability compared with the STACK that used past electrolyte membrane." 15 


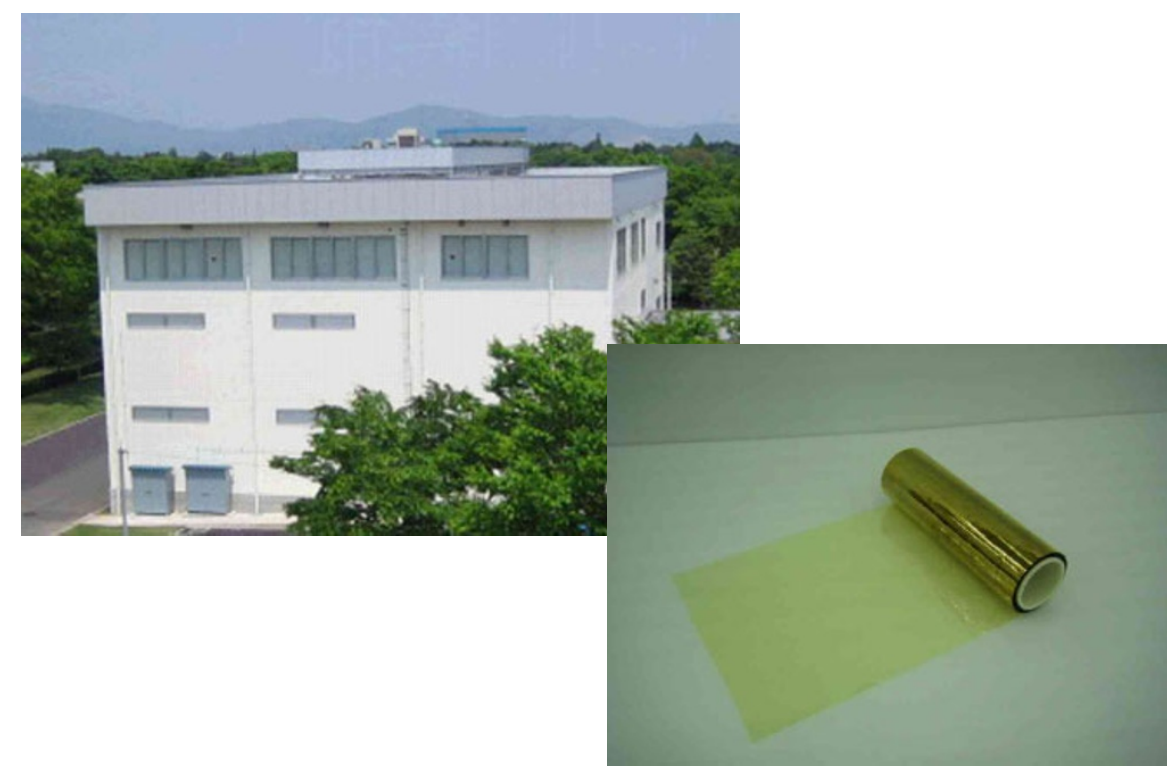

Figure 19. Semi-commercial plant and an example of product.

Honda has released in the press about the development of the next generation fuel cell stack «Honda FC STACK $\gg$ that can be operate at $-20^{\circ} \mathrm{C}$ that used $<$ Aromatic Electrolytic Membrane $>$ and the start of the public road examination of $\ll \mathrm{FCX} \gg$ that installed this new stack, in October $10,2003^{13}$ before the above-mentioned release of JSR.

Acknowledgment. In recognition of the outstanding development in polymer technology, we received the Award of the Society of Polymer Science, Japan (2006). We are most grateful to research staffs of Honda R\&D Co., Ltd. who encouraged us to accomplish our electrolyte membrane's merits. We are also grateful to researchers and staffs of JSR (Research Fellow Laboratory at Tsukuba, Material Characterization \& Analysis Lab., Process Development \& Engineering Dept., Business Development Dept., Research \& Development Dept. and Intellectual Property Dept.) for support.

Received: September 17, 2008 Accepted: November 3, 2008 Published: December 17, 2008

\section{REFERENCES}

1. M. Hickner, H. Ghassemi, Y. S. Kim, B. R. Einsla, and J. E. McGrath, Chem. Rev., 104, 4587 (2004).

2. a) A. Noshay and L. M. Robeson, J. Appl. Polym. Sci., 20, 1885 (1976).

b) K. D. Kreuer, Solid State Ionics, 97, 1 (1997).

c) T. Kobayashi, M. Rikukawa, K. Sanui, and N. Ogata, Solid State Ionics, 106, 219 (1998).

d) K. D. Kreuer, J. Membr. Sci., 185, 29 (2001).

e) K. Miyatake, Y. Chikashige, and M. Watanabe, Macromolecules, 36, 9691 (2003)
3. a) M. Ueda, H. Toyota, T. Ochi, J. Sugiyama, K. Yonetake, T. Masuko, and T. Teramoto, J. Polym. Sci., Polym. Chem. Ed., 31, 853 (1993).

b) F. Wang, M. Hickner, Q. Li, W. Harrison, J. Mecham, T. A. Zawodzinski, and J. E. McGrath, Macromol. Symp., 175, 387 (2001). c) K. Miyatake, H. Zhou, H. Uchida, and M. Watanabe, Chem. Commun., 368, (2003).

d) B. Bae, K. Miyatake, and M. Watanabe, J. Membr. Sci., 310, 110 (2008).

4. a) N. Asano, K. Miyatake, and M. Watanabe, Chem. Mater., 16, 2841 (2004).

b) K. Miyatake, N. Asano, and M. Watanabe, J. Polym. Sci., Part A: Polym. Chem., 41, 3901 (2003).

c) K. Okamoto, K. Matsuda, Z. Hu, K. Chen, N. Endo, and M. Higa, ECS Trans., 12 (2008).

5. D. A. Hajduk, P. E. Harper, S. M. Gruner, C. C. Honeker, G. Kim, E. L. Thomas, and J. L. Fetters, Macromolecules, 27, 4063 (1994).

6. H. Mita, "Degradation and Stabilization of Polymers," H. H. Jellineck, Ed., Elsevier Chapter 6, 1978.

7. S. Oae, "Chemistry of Sulfur Compouds (in Japanese)," KagakuDojin Tokyo, 1969, Vol. 2, Chapter 10, p. 415.

8. a) I. Colon and D. R. Kelsey, J. Org. Chem., 51, 2627 (1986). b) M. Ueda and F. Ichikawa, Macromolecules, 23, 926 (1990). c) Y. Wang and R. P. Quirk, Macromolecules, 28, 3495 (1995).

9. C. Genies, R. Mercier, B. Sillion, N. Cornet, G. Gebel, and M. Pineri, Polymer, 42, 359 (2001).

10. a) F. Wang; M. Hickner, Y. S. Kim, T. A. Zawodzinski, and J. E. McGrath, J. Membr. Sci., 197, 231 (2002).

b) M. T. Bishop, F. E. Karasz, P. S. Russo, and K. H. Langley, Macromolecules, 18, 86 (1985).

11. D. S. Watkins, "Fuel Cell Systems," Plenum Press, New York, 1993.

12. http://www.jsr.co.jp/news/2006/news060125.shtml

13. http://www.honda.co.jp/news/2003/4031010.html

14. a) http://www.honda.co.jp/news/2004/4040226.html

b) http://www.honda.co.jp/news/2004/4041117a.html

c) http://www.honda.co.jp/news/2005/4050127-fcx.html

15. http://www.honda.co.jp/factbook/auto/fcx/200412/04.html 


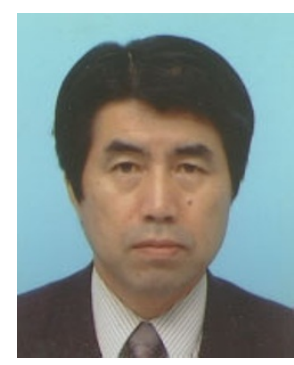

Dr. Kohei Goto was born in Osaka in 1948. He received his MS degree from Kyoto Institute of Technology in 1972, and his Ph. D degree from Kyusyu University in 1989 for the study of $p$-aramide-based molecular composites under the supervision of Professor Motowo Takayanagi and Professor Tisato Kajiyama. He joined JSR Corporation in 1972 and began his research work from 1974 up to the present at Tokyo Research Laboratories, Yokkaichi Research Laboratories and Tsukuba Research Laboratories. He became a research fellow in his Corporation in 2001. His research interests comprise the design of new functional aromatic polymers for special applications. In his research activity, Ichimura Foundation already awarded him in 1995 for the development of low temperature processing alignment coating of alicyclic polyimides for full-color activematrix LCD. The Photopolymer Science and Technology Award was given to him for the polymer design of low-dielectric aromatic polyimides in 2002. He is also a recipient of the Award of the Society of Polymer Science, Japan (2006). He is an author and co-author of $c a .50$ original papers, reviews and books and $c a .320$ applied patents. He is now a SPSJ Fellow in 2008.

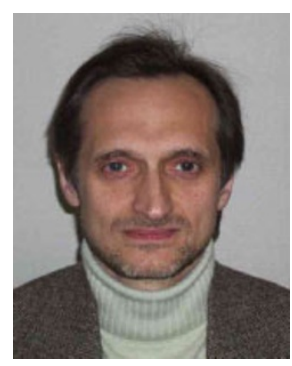

Dr. Igor Rozhanskii was born in Tula region, Russia in 1961. He received his MS degree from the Chemistry Department of the Moscow State University in 1984, and his Ph. D. degree from the same department in 1988. In the same year, he joined a Russian company "NPO Stekloplastic," to be engaged in R\&D projects dealing with glass fiber technologies. He entered Japan in 1993 as a post-doc scientist in Tokyo Institute of Technology, working in the field of organometallic polymers under the supervision of Professor Takeshi Endo. He joined JSR Corporation in 1996, and started his R\&D work in Tsukuba Research Laboratories. He has been mainly engaged in design and synthesis of high-performance polymers, including polyimides, polyarylenes and other materials for special applications, such as electronics, optics and fuel cells. He is a recipient of the Award of the Society of Polymer Science, Japan (2006).

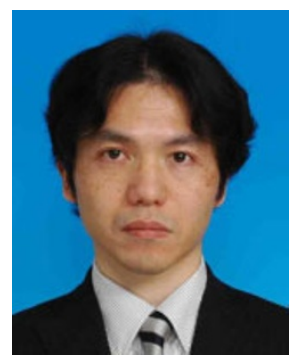

Dr. Yoshitaka Yamakawa was born in Mie in 1966. He received his MS degree from Nagoya University in 1991, and his $\mathrm{Ph}$. D. of Engineering from Yamagata University in 2000 under the supervision of Professor Mitsuru Ueda. He joined JSR Corporation in 1991. He has been mainly engaged in the R\&D of synthesis of functional polymers, such as poly(amino acid)s derivatives, dendrimers and polymer electrolyte membranes. During 19961999, he worked at Joint Research Center for Precision Polymerization, Japan Chemical Innovation Institute. He is a recipient of the Award of the Society of Polymer Science, Japan (2006).

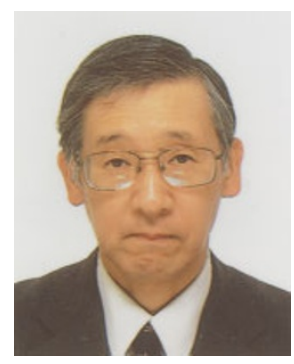

Dr. Toshihiro Otsuki was born in Wakayama in 1956. He received his MS degree in 1981 from Osaka University, and $\mathrm{Ph}$. D degree of Engineering in 1991 from Tokyo Institute of Technology under the supervision of Professor Yoshio Imai. He jointed JSR Corporation in 1981. He has been mainly engaged in the R\&D in the field of plastics, such as ABS resin, transparent polyamide, heat resistant transparent resin (trade-name ARTON) and polymer electrolyte membranes for fuel cells. He has received the Award of the Society of Chemical Engineers, Japan in 1996 for the development and industrialization of heat resistant transparent resin. He is also a recipient of the Award of the Society of Polymer Science, Japan (2006).

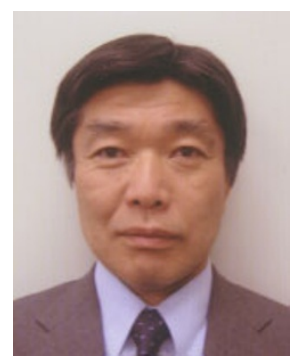

Yuji Naito was born in Kanagawa in 1952. He graduated from Sagamidai Technical High School in 1971. In the same year he joined JSR Corporation and continued research work in Central Research Laboratories, Tokyo Research Laboratories, Tsukuba Research Laboratories and Research Fellow laboratory. He has been engaged in polymer physics and processing of manufacturing polymers, such as photo-reactive polymer coatings for optical fibers and polymer electrolyte membranes for fuel cells. He is a recipient of the Award of the Society of Polymer Science, Japan (2006). 